Article

\title{
Preventing Air Pollution Connected to the Explosion of Different Types of Flours in Dedicated Storage and Transportation Systems
}

\author{
Marzena Półka *(i) and Szymon Ptak \\ The Main School of Fire Service, 52/54 Słowackiego St., 01-629 Warsaw, Poland; sgsp@sgsp.edu.pl \\ * Correspondence: mpolka@sgsp.edu.pl; Tel.: +48-22-56-17-712
}

Received: 15 November 2019; Accepted: 13 December 2019; Published: 17 December 2019

check for updates

\begin{abstract}
Air pollution, caused by explosion and/or fire of flammable substances, is typical for the majority of technological processes, e.g., flour storage and transportation systems in the food industry. If explosion venting systems are not properly designed, an explosion might lead to many causalities, substantial losses, and significant release of combustion products into the ambient atmosphere. This article presents a study on four selected types of flours: rice flour, oat flour, cornmeal, and chickpea flour. The chosen ignition and explosion indices were determined (heat of combustion, $\left.p_{\max }(\mathrm{dp} / \mathrm{dt})_{\max }\right)$ and TGAs were conducted. The results were used to calculate the explosion venting area according to EN 14491. Despite similar origins, samples were characterized by slightly different courses of explosion, leading to significant differences in required venting areas. Chickpea dust was found to be the most distinguishing sample with the highest values of $p_{\max }(\mathrm{dp} / \mathrm{dt})_{\max }$, and $\mathrm{K}_{\mathrm{St}}$ recorded $(7.7 \mathrm{bar}, 313.08 \mathrm{bar} / \mathrm{s}$, and $85 \mathrm{mbar} / \mathrm{s}$, respectively). To avoid structure failure resulting in the emission of pollutants into the atmosphere, a change in the stored flour type should be preceded by a revision of safety measures taken, as the required vent area might differ significantly depending on the $\mathrm{K}_{\mathrm{St}}, \mathrm{L} / \mathrm{D}$ ratio, and desired maximum static pressure.
\end{abstract}

Keywords: air pollution; explosion safety; safe storage; food industry

\section{Introduction}

\subsection{Dust Explosions and Changes in the Environment}

The susceptibility of a dust and air mixture to ignition and explosion is one of the most pronounced fire hazards in industry which concurrently causes changes in the environment and in air composition. Explosions and dusts fires have been accompanying man since the time when he started to produce, process, store, and haul flammable materials for crushing to the form of dust. Grain silos and other agricultural devices designated for reloading or processing of products are particularly susceptible to explosions. Hence, it is necessary to learn the explosion parameters of flour dusts and to deploy new green technologies to prevent the destruction of plant infrastructure and degradation of the natural environment along with airborne contamination.

During the technological process and during its transfer, products tends to become crushed. Generally, in grain reloading devices, particles of sizes of 17 to 120 micrometers are produced $[1,2]$. Introduction of a volume or concentration of solid, liquid or gaseous substances to the atmosphere that are hazardous for the environment and, along with a release of thermal energy and pressure waves, is one of the main factors that cause the contamination of surrounding air. Dust or introduced energy are able to remain in the atmosphere for a certain period of time which, as a result, significantly changes the composition of air and may also cause adverse consequences for the biosphere or other 
environmental elements. According to the World Health Organization, dusts and combustion products form air pollution which have an adverse impact on health or is dangerous for other reasons such as a reduced visibility [3].

Dust explosion in a working place poses a serious hazard for the life and health of employees involved. Over the years, numerous events have been recorded during which dust explosions have caused the death of numerous individuals and considerable property losses. Conducted analyses on data concerning explosions of flammable dusts indicate that their highest number occurred in plants associated with the food industry [4-6].

Statistical data show that in the period of 1785-2012 in the USA, 1611 explosions and fires were recorded involving flammable dusts. As many as 645 (approximately $40 \%$ ) of those events occurred in plants that produce foodstuffs. On the other hand, in Europe over 800 such events have been recorded, the highest number of which took place in Germany and Great Britain [7].

One of the first-ever documented events connected with the explosion of dust in the food industry was a case in 1785 in which flour exploded in a bakery in Turin, Italy. The explosion caused the bakery's windows to shatter and damaged the building's structure. Due to the spread of a very large amount of flour, it became airborne and a dust-air cloud formed which was then ignited by a lamp [1].

In 1878, one morning in Washburn, Minnesota, in a seven-story mill [8], three consequent explosions took place as a result of which the entire 14 person crew of the night shift lost their lives. A further four persons died due to the spread of the fire to adjacent buildings. During the investigation, it was found that the ignition of the dust cloud had been initiated due to the fact of a spark created by two insufficiently moistened millstones rubbing against each other. This incident led to the introduction of significant reforms in the milling sector in the USA, with a focus on the installation of appropriate ventilation systems and other protection devices.

Another example, which took place in April 2013 in Statesville, USA [9], was the explosion of grain dust in a mill.

Dust explosions within the food industry has been the focus of a number of studies. In one study, the explosion and flammability parameters of seven dusts-icing sugar, maize, wheat and barley grain dust, alfalfa, bread-making wheat, and soybean dust-were tested [10]. The paper discusses the factors that affect the course of explosions analyzing the maximum value of maximum rate of explosion pressure rise $(\mathrm{dp} / \mathrm{dt})_{\max }$. The parameters were determined with the use of standardized procedures to reconstruct real industrial conditions. The most difficult factors to predict are the source of ignition or the actual initial conditions prior to the explosion in the food processing industry. Among the studied materials, icing sugar was the most sensitive material, scoring highest for ignition, while soybean dust was the least prone to ignition by a hot surface. The values of the minimum ignition temperatures of wheat grain dust and bread-making wheat were found to be the most dangerous in this context. On the other hand, the values obtained for the barley grain dust and alfalfa were the highest. Similar dependencies were observed in the case of $\mathrm{p}_{\max }$ and $(\mathrm{dp} / \mathrm{dt})_{\max }$ parameters.

\subsection{Conditions Required}

Explosive dust-air mixtures may be formed during the storage of such raw materials such as grains, sugar, flour, transport (e.g., in bucket conveyors). This implies that an explosion may take place outside of those devices. Particular hazards are related to the formed dust deposits or in the interiors of production equipment, inside of which the flammable dust is generated, transported, relocated, processed or dried, etc. For example, as a result of sudden air swirling or an explosion inside the device, settled dust may become airborne and may form a dangerous dust-air cloud of an explosive concentration which may then become ignited from an effective ignition source. The main factors that have an impact on ignition of a dust and air mixture and force of the explosion are [11]:

- Chemical composition of dust particles, as different chemical compounds burn in different ways, and the dimensions of dust particles, as smaller grains burn more rapidly which causes an increase in explosion parameters as the size of dust particles decreases; 
- Dust humidity, as increased moisture contents in the dusts impedes its combustion.

- Concentration of oxygen and dust, as tthe concentration of a dust and air mixture must be above the lower explosive limit (LEL). The strongest explosion takes place at concentrations that reach the level of the stoichiometric concentration. On the other hand, an increased oxygen concentration in the surroundings will increase the hazard.

The most obvious approach to prevention of explosions is to eliminate the factors necessary to cause an explosion. In the European Union (EU), those principles have been determined in the ATEX directive and are referred to as the "principles of integrated safety". They are deployed in the following sequences [12]:

- Modification of the technical processes to limit the occurrence of flammable dust, particularly a quantity that would not allow the formation of a mixture over LEL;

- Reducing the concentration of oxidizing agents in production or warehouse facilities;

- Preventing the formation of mixed flammable dust with air (formation of a cloud);

- Full elimination or minimizing the possibility of occurrence of effective ignition sources;

- $\quad$ Limiting the range of flames and explosion pressures.

- Adoption of means aimed at limiting the consequences of explosions, i.e., the range of flame and impact of explosion pressure.

Minimizing the consequences of explosions may be divided into the following three groups [13]:

1. Structures resistant to the explosion pressure or impact of explosion pressure;

2. Explosion venting, i.e., adoption of devices designated to reduce the pressure created as a result of the explosion and disposal of combustion products to the outside of the installations. Explosion venting systems are one of the most popular means of protection. The effective explosion requires the area of the ventilation devices to be determined. Such technical standards as the NFPA 68 and the standard EN 14491 provide guidelines and models that enable calculating the surface of the vents. There are also solutions in place which enable flameless explosion venting;

3. Insulating the protected volume $[5,14]$ which may be executed in three ways: formation of powder barriers inside conduits; stopping the flame with the use of quick closing valves; and/or redirecting the explosion into another space (explosion channels-diverters).

The powder barrier acts by forming in the conduit of a high concentration of extinguishing powder which prevents the permeation of flame to the protected volume.

It is crucial to determine safe distances from openings in the installation through which combustion products would be released (for example, after opening of the so-called explosion vent). Empirical correlations are often used to estimate safety distances in case of dust explosions. In Europe, there are two main calculation methods available in VDI 3673 and EN 14491. The first standard (VDI 3673) introduces formulas based on experimental investigations of vented dust explosions using large vessels and estimated external explosion. The latter standard (EN 14491) describes the correlation derived from data recorded by Skjeltorp, Jenssen, and Rinnan [15]. It is based on small-scale experiments with TNT explosions in an ammunition storage facility.

Reference [16] describes the difficulties in assessing external overpressures during a dust explosion, as it is dependent on such factors as the position of the ignition source, the vent area, the volume of the vessel, the vent opening pressure (i.e., static pressure $p_{\text {stat }}$ ), the quantity of combustible dust inside the vessel, and present obstacles which, in fact, will intensify the turbulence and, hence, affect the combustion dynamics. At the same time, obstacles present inside the vessel can cause additional compression and, therefore, lead to higher maximum explosion pressures. The author compared the outcomes of the experiments with the empirical formulas proposed by the technical standards.

There are technical standards [17-19] that describe the calculation method of the required venting devices depending on the type of dust, conditions of its transport, and numerous other factors. 
The vent area versus reduced explosion pressure $\left(\mathrm{p}_{\text {red }}\right)$ has been analyzed [20] by calculating different silo dimensions, materials (barley and wheat flour), and values of the inertia and activation pressure of the venting devices. Bursting panels, explosion doors, and light-weight concrete slabs have been tested. The results showed that increasing the venting area is not necessary for explosion doors when the silo volume is bigger or equal to $60 \mathrm{~m}^{3}$ but the mass of the venting element in relation to the vent area is lower than $20 \mathrm{~kg} / \mathrm{m}^{2}$ considering that EN 14491 might be directly applied. For other conditions, inertia effects should be tested or, alternatively, the method outlined in NFPA 68 should be used.

The influence of the length/diameter ratio on total vent area for four different vessels with different geometries has been studied [21]. The tests were carried out with wheat flour and maize starch using the length/diameter ratio in the empirical correlations from standards EN 14491 and NFPA 68. The results showed significant differences in the outcomes of the calculations performed according to both standards. The research [21] showed that long pipes are prone to flame acceleration. A transition from deflagration into detonation is possible, with the overpressures reaching dozens bar. Therefore, the analysis of the most likely flame propagation characteristics is crucial for proper explosion safety assessment [22].

\section{Materials and Methods}

\subsection{Materials}

As described in previous sections, explosions in the food industry constitute a major challenge. There is little research published describing the impact of explosion indices on the real safety considerations. Therefore, it was decided to focus on flours of various types. A similar origin of the samples might lead to considerable differences in desired safety levels. Moreover, the samples chosen enable the adoption of the research in the food industry.

Four types of dust were used in the testing:

- $\quad$ Rice flour dust;

- Cornmeal dust;

- Oat flour dust; and

- Chickpea flour dust.

The tested dust came from the plant of Melvit S.A. Flour dusts were sieved through a sieve with mesh size of $63 \mu \mathrm{m}$. The equipment used was a laboratory sieve shaker manufactured by Multiserw Morek Company with a test sieve diameter equal to $300 \mathrm{~mm}$.

Transient moisture content was determined for the test samples using a Radwag MAC-50/NH moisture analyzer.

Table 1 provides the specification used for the bulk density and transient moisture content of the tested dusts.

Table 1. Characteristics of tested dust types: bulk density and contents of transient humidity.

\begin{tabular}{ccccc}
\hline & Chickpea Flour & Rice Flour & Cornmeal & Oat Flour \\
\hline Bulk density $\left(\mathrm{g} / \mathrm{dm}^{3}\right)$ & 340 & 580 & 540 & 344 \\
Moisture content $\left(\mathrm{mass}^{2}\right)$ & 9.5 & 9.12 & 10.02 & 10.17 \\
\hline
\end{tabular}

There was a significant difference in the determined bulk density of chickpea flour and oat flour compared to the rice flour and cornmeal.

The selection of samples depended on their availability on the market and the possibility of comparing the actual impact on explosive safety in actual conditions. This was due to the fact that production plants may change the type of stored or transported flour depending on the direction of production development arising from market conditions. 


\subsection{Methods}

\subsubsection{Testing Consistent with Standard EN 14034}

Experimental testing was conducted in conformity with the following standards:

- EN 14034-1 Determination of the maximum explosion pressure $p_{\max }$ of a dust cloud [23];

- EN 14034-2 Determination of the maximum rate of explosion pressure rise $(\mathrm{dp} / \mathrm{dt})_{\max }$ of dust cloud [24];

- $\quad$ EN 14034-3 Determination of the lower explosion level of a dust cloud [25].

Testing was performed with the use of a testing stand setup in conformity with the standards EN 14034. The main component of this stand was the research chamber, sphere-shaped, with a capacity of $20 \mathrm{dm}^{3}$. The dust to be tested was inserted in the dust container with a capacity of $0.6 \mathrm{dm}^{3}$, in which overpressure was generated at the level of $0.2 \mathrm{MPa}$. Next, through the solenoid valve, a dust dose was placed in the testing chamber through a dispersion nozzle, through which dust was dispersed throughout the entire spherical volume. From opening of the solenoid valve until ignition, there was a delay time of approximately $60 \mathrm{~ms}$. Ignition was initiated by a chemical explosive which consisted of ignition heads installed inside the sphere. For needs of the determination of lower explosive limit (LEL) in conformity with the standard PN-EN 14034, use was made of one ignition head with a capacity of $2 \mathrm{~kJ}$. For testing of the $p_{\max }$ and $(\mathrm{dp} / \mathrm{dt})_{\max }$, two heads were used, each with a capacity of $5 \mathrm{~kJ}$. The producer of the used heads was Nitroerg S.A.

A positive test result was obtained when the measured accrual of pressure inside the sphere was larger or equal to 0.5 bar. In order to determine the maximum explosion pressure $p_{\max }$ for the given dust, it was necessary to perform a series of tests, starting with the concentration of $250 \mathrm{~g} / \mathrm{m}^{3}$. In subsequent trials, the concentration was increased by $250 \mathrm{~g} / \mathrm{m}^{3}$ or reduced by $50 \%$ in relation to the previous one. Trials were repeated until the maximum explosion pressure could be determined. The maximum explosion pressure $\mathrm{p}_{\max }$ of the dust clouds was determined in at least two consequent growing and decreasing concentrations for which the maximum explosion pressure $\mathrm{p}_{\max }$ for those concentrations was lower. The maximum explosion pressure constitutes the mean arithmetic value of three series of measurements.

Testing of the maximum rate of explosion pressure rise $(\mathrm{dp} / \mathrm{dt})_{\max }$ of dust clouds was carried out according to the standard EN 14034-2 [24] also in a spherical testing chamber with a volume of $20 \mathrm{dm}^{3}$. To determine the maximum explosion pressure $\mathrm{p}_{\max }$ for the given dust, it was necessary to conduct a series of tests starting with the concentration of $250 \mathrm{~g} / \mathrm{m}^{3}$. In subsequent trials, the concentration was increased by $250 \mathrm{~g} / \mathrm{m}^{3}$ or reduced by $50 \%$ in relation to the preceding one. Trials were continued until it was possible to determine the maximum rate of explosion pressure rise. The maximum rate of explosion pressure rise $(\mathrm{dp} / \mathrm{dt})_{\max }$ of dust clouds was determined if, for at least two growing and decreasing concentrations, the maximum rate of explosion pressure rise $(\mathrm{dp} / \mathrm{dt})_{\max }$ for those concentrations was lower. The maximum rate of explosion pressure rise determined in such a way constituted the $(\mathrm{dp} / \mathrm{dt})_{\max }$ of the first series. In line with the standard, two further series of measurements should be carried out, and $(\mathrm{dp} / \mathrm{dt})_{\max }$ for the given dust was constituted by the mean arithmetic of a series of three measurements. Taking into consideration the fact that increasing the explosion pressure tends to decrease as the volume grows, and to calculate $\mathrm{K}_{\max }, \mathrm{K}_{\mathrm{st}}$, the so-called cubic law, should be adopted to enable the correct interpolating of test results [24]:

$$
\mathrm{K}_{\mathrm{St}}=\mathrm{K}_{\max }=\sqrt[3]{0.02} \cdot\left(\frac{\mathrm{dp}}{\mathrm{dt}}\right)_{\max , 201}=0.2714 \cdot\left(\frac{\mathrm{dp}}{\mathrm{dt}}\right)_{\max , 201},
$$

Testing of the LEL of dust clouds were conducted in conformity with the standard EN 14034-3 [25].

To determine the LEL for the given dust, a series of tests were necessary, starting with the concentration of $500 \mathrm{~g} / \mathrm{m}^{3}$. In subsequent trials the concentration was increased by $250 \mathrm{~g} / \mathrm{m}^{3}$ or reduced by $50 \%$ in relation to the preceding one. Trials were continued until the lower explosiveness level could 
be determined. The LEL of dust clouds was determined as the highest concentration at which the test result is negative. In order to confirm the test results, two additional measurements were carried out for the concentration determined in the first series of measurements as LEL.

\subsubsection{Thermogravimetric Analysis}

In order to determine the characteristics of the thermal decomposition process and the process of changes that took place in the selected types of flour dusts within a pre-set temperature range, samples were tested using a TA INSTRUMENTS Q500 thermogravimeter. Flour samples, weighed at approximately $30 \mathrm{mg}$, were subjected to a thermogravimetric analysis (TGA) in the dynamic method in conformity with the standard EN ISO 11358 [26]. The measurements were performed within a temperature range of $20^{\circ} \mathrm{C}$ to $800{ }^{\circ} \mathrm{C}$ at a constant heating rate of $10^{\circ} \mathrm{C} / \mathrm{min}$. An oxidizing atmosphere (air) was obtained by maintaining a constant air flow of $90 \mathrm{~mL} / \mathrm{min}$ and flow of inert gas (nitrogen) of $10 \mathrm{~mL} / \mathrm{min}$. Based on our own research, the adopted measurement precision was as follows: temperature: $1{ }^{\circ} \mathrm{C}$; sample weight: $0.01 \mathrm{mg}$; mass loss rate: $1{ }^{\circ} \mathrm{C} / \mathrm{min}$.

\subsubsection{Heat of Combustion}

Determination of the combustion heat of the tested dusts was performed with the use of a bomb calorimeter according to the standard EN ISO 1716 [27]. A sample of selected dust, of a weight of up to $1 \mathrm{~g}$, was burnt in the oxygen atmosphere at a pressure of $2 \mathrm{MPa}$, at an initial temperature of approximately $20^{\circ} \mathrm{C}$, maintained at constant volume in the calorimetric setup. Then, samples underwent complete combustion, after which the total heat released from the sample was determined in relation to its mass.

\subsubsection{Vent Area Calculation}

Calculation of the minimum area of explosion relieving devices was performed with the use of empirical dependencies described in the standard EN 14491.

For the needs of executing the correct calculations, several basic data were required, such as [21]:

- The desired value of reduced explosion pressure, $\mathrm{p}_{\text {red, }}$, which depends on the structural strength and in no case may be exceeded;

- Values specifying the explosiveness of flammable dusts, first of all coefficient, $\mathrm{K}_{\mathrm{St}}$, and the maximum explosion pressure $\mathrm{p}_{\max }$;

- Characteristics of the process installation, in particular the volume, $\mathrm{V}$, and the length/diameter ratio (L/D);

- Characteristics of the venting device and its activation (static) pressure $\mathrm{p}_{\text {stat }}$.

Initial values were chosen for the calculations. They were typical for some silos used in the storage of goods, such as flours or cereal grains, protected by typical devices available on the market:

(1) Explosion venting device:

- Dimensions: $500 \times 1000 \mathrm{~mm}$ (rectangular); geometric venting area: $A_{f}=0.5 \mathrm{~m}^{2}$.

- Minimal burst (gauge) pressure: $p_{\text {stat }}=50 \pm 15$ mbar.

- Material: steel/PTFE/stainless steel.

- Venting efficiency of the device: $E_{f}=1$ (geometric venting area $A_{f}$ equal to required venting area $A$ ).

(2) Protected silo:

- Pneumatic conveying with axial introduction into the silo.

- Volume: $V=215 \mathrm{~m}^{3}$. 
- Diameter of the conveying pipe: $D_{F}=200 \mathrm{~mm}$.

- Reduced explosion (gauge) pressures: $p_{\text {red,max }} \in\{0.12$ bar; 0.25 bar; 0.4 bar $\}$.

- Length: $L=6.5 \mathrm{~m}$ (diameter $D$ set as a variable).

To calculate the value of the relieving surface for a silo, to which material was inserted axially, the following dependencies, Equations (2)-(4), were used [18]:

$$
\begin{gathered}
A=0.1 \cdot L \cdot X(1+Y \cdot \log (L / D)), \\
X=\left(\frac{1}{D_{z}} \cdot\left(8.6 \cdot \log p_{\text {red, }, \max }-6\right)-5.5 \cdot \log p_{\text {red, } \max }+3.7\right) \cdot 0.011 \cdot K_{S t} \cdot D_{F}, \\
Y=1.0715 \cdot p_{\text {red, } \text { max }^{\prime}}^{-1.27}
\end{gathered}
$$

\section{Results}

\subsection{Explosion Parameters}

The conducted trials enabled the determination of basic explosiveness parameters of the tested

\begin{tabular}{|c|c|c|c|c|c|c|c|}
\hline & $\begin{array}{l}\text { Dust } \\
\text { Concentration } \\
\text { for } \mathrm{p}_{\max }\left(\mathrm{g} / \mathrm{m}^{3}\right)\end{array}$ & $\begin{array}{c}\text { Value of } \\
p_{\max }(\text { bar) }\end{array}$ & $\begin{array}{l}\text { Concentration } \\
\text { for }(d p / d t)_{\max } \\
\qquad\left(g / \mathrm{m}^{3}\right)\end{array}$ & $\begin{array}{l}\text { Value of } \\
(\mathrm{dp} / \mathrm{dt})_{\max } \\
\text { (bar/s) }\end{array}$ & $\begin{array}{c}\text { LEL } \\
\left(\mathrm{g} / \mathrm{m}^{3}\right)\end{array}$ & $\begin{array}{l}\text { Value of } \\
\mathrm{K}_{\mathrm{St}} \\
(\mathrm{bar} \cdot \mathrm{m} / \mathrm{s})\end{array}$ & $\begin{array}{c}\text { Dust } \\
\text { Explosion } \\
\text { Class St }\end{array}$ \\
\hline Cornmeal dust & 750 & 7.1 & 1000 & 203 & 125 & 55 & 1 \\
\hline Rice flour dust & 1000 & 6.7 & 1000 & 186 & 250 & 51 & 1 \\
\hline $\begin{array}{l}\text { Chickpea flour } \\
\text { dust }\end{array}$ & 750 & 7.7 & 750 & 313 & 60 & 85 & 1 \\
\hline Oat flour dust & 1000 & 7.0 & 1000 & 259 & 125 & 70 & 1 \\
\hline
\end{tabular}
foodstuff dusts. Table 2 presents the results of the determined parameters for the selected dusts.

Table 2. The results of the determined explosion parameters.

The value of $\mathrm{p}_{\max }$ of three consecutive measurements did not differ more than $10 \%$. Typically, the $\mathrm{K}_{\mathrm{St}}$ value is determined with uncertainty lower than $20 \%$, for $\mathrm{K}_{\mathrm{St}}$ values between 51 and $100 \mathrm{bar} \cdot \mathrm{m} / \mathrm{s}$.

While making an analysis of the obtained results of the maximum explosion pressure of flammable dusts, attention should be drawn to the fact that this is a parameter that will have a significant impact on damage if the explosion does take place. For all types of dust, positive results were recorded during the trial determination of the maximum explosion pressure. Values for $p_{\max }$ of the tested foodstuff dusts were within the range of 6.7 bar to 7.7 bar. The highest values for the maximum explosion pressure were recorded for chickpea flour dust. The lowest result for $\mathrm{p}_{\max }$ was recorded for the cornmeal dust. The highest $p_{\max }$ value achieved among the dusts was $14 \%$ higher than the lowest $p_{\max }$ value.

The maximum rate of explosion pressure rise was determined by the rate at which the overpressure wave spreads. This parameter will also be of considerable importance for the volume of damage ensuing from explosion. Values $(\mathrm{dp} / \mathrm{dt})_{\max }$ of the tested foodstuff dusts were within the range from 186 bar to 313 bar. The highest values of the maximum rate of explosion pressure rise were recorded for chickpea flour dust. The lowest result $(\mathrm{dp} / \mathrm{dt})_{\max }$ were recorded for cornmeal. The highest $(\mathrm{dp} / \mathrm{dt})_{\max }$ value was $168 \%$ higher than the lowest $(\mathrm{dp} / \mathrm{dt})_{\max }$ value.

The lower explosiveness level defines the concentration of flammable dust which leads to an explosion hazard. This parameter is of great importance, as it critical to ensuring safe working conditions and an appropriate choice of anti-explosion protection means. The obtained LEL values were within the range of $60 \mathrm{~g} / \mathrm{m}^{3}$ to $250 \mathrm{~g} / \mathrm{m}^{3}$. The lowest value of the lower explosiveness level was recorded for chickpea flour dust. The highest LEL value was recorded for the cornmeal dust. The lower explosion level of chickpea flour dust was over $400 \%$ lower than that of the rice flour dust.

In general, among the tested samples, the chickpea flour dust was considered as the most dangerous in the context of explosion safety. The results showed that the optimal dust concentration 
for the chosen flours was found to be within the range of 750 to $1000 \mathrm{~g} / \mathrm{m}^{3}$, i.e., the highest values of $\mathrm{p}_{\max }$ and $\left.(\mathrm{dp} / \mathrm{dt})\right)_{\max }$ obtained. Despite the differences, all the dusts were described by the St 1 class.

\subsection{TG Analysis}

Table 3 lists the characteristic temperatures of the thermal decomposition of the particular samples.

Table 3. Results of testing the thermal decomposition of the samples.

\begin{tabular}{ccccc}
\hline & Chickpea Flour Dust & Rice flour Dust & Cornmeal Dust & Oat Flour Dust \\
\hline Temperature of the beginning of thermal & 252 & 288 & 288 & 283 \\
decomposition $\left({ }^{\circ} \mathrm{C}\right)$ & 303 & 302 & 305 & 301 \\
Temperature of 50\% sample mass loss $\left({ }^{\circ} \mathrm{C}\right)$ & 286 & 303 & 307 & 299 \\
Temperature of maximum mass loss $\left({ }^{\circ} \mathrm{C}\right)$ &
\end{tabular}

The similar origin of the samples (i.e., organic foodstuffs) caused a similar course of the thermal decomposition. Only chickpea flour sample was found to have an earlier commencement of thermal decomposition (by approximately $30 \mathrm{~K}$ ) and a lower temperature of the maximum loss rate of sample mass (by approximately $15 \mathrm{~K}$ ).

Figure 1 presents the courses of thermal decomposition obtained during the thermogravimetric analysis, and Figure 2 shows the course of derivative values of sample mass loss over time.

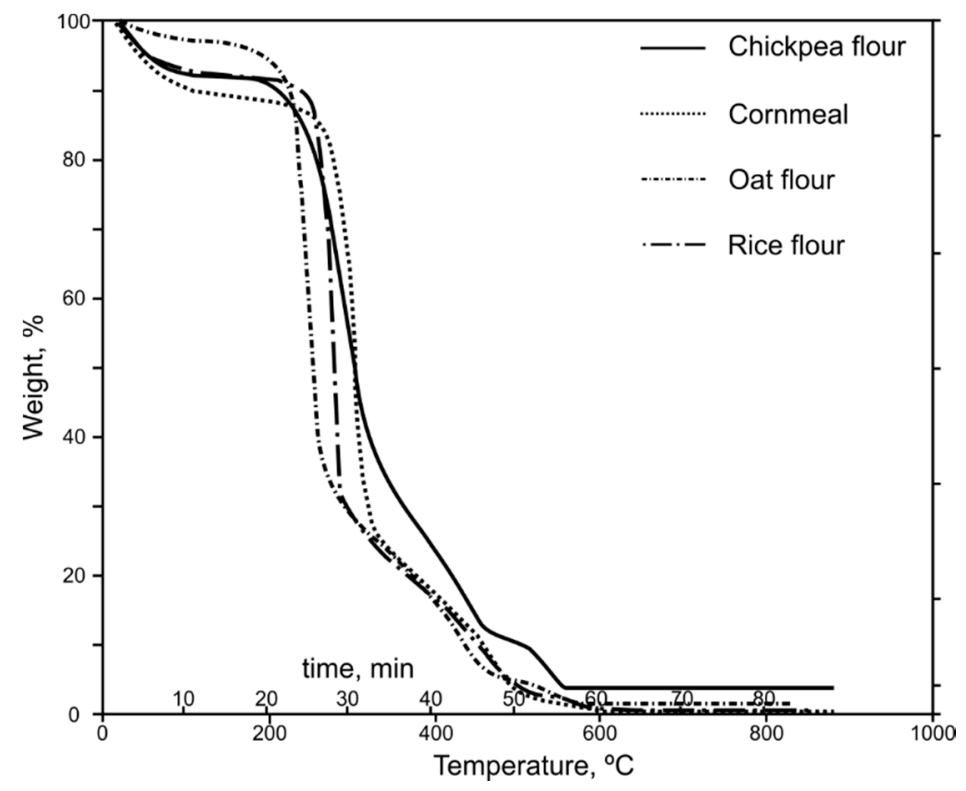

Figure 1. Presentation of the courses of thermal decomposition for the particular samples.

Results of the conducted thermogravimetric analysis of the samples point to the complex courses of thermal decomposition. The course characterized by the biggest deviation from the other samples was found for chickpea flour which was characterized by slightly more pronounced peaks of derivatives of sample mass loss in temperatures of more than 400 and $500{ }^{\circ} \mathrm{C}$. Consequently, the results of the thermogravimetric analysis indicate that similar explosion parameters of the samples may be expected, and, consequently, a similar required explosion safety level minimizing the risk of releasing combustion products that are hazardous for the environment. The proposed thesis is verified in the following subsections.

In general, the comparable origin of the test samples was reflected in the TGA results shown in Figures 1 and 2. The recorded course of thermal decomposition, with minor exceptions, was similar for all tested samples. Slight differences were observed for the chickpea flour as reflected in the lower values of the characteristic temperatures as described in Table 3. It is supposed to correlate with a 
more severe course of explosion, as described in the previous section, observed for the sample in comparison to the others. Moreover, it is supposed that there might be a connection between the course of thermal decomposition and lower value of bulk density (as described in Table 1), as it will lead to better diffusion of both volatile compounds and the oxygen from/to the dust particles during the experiments.

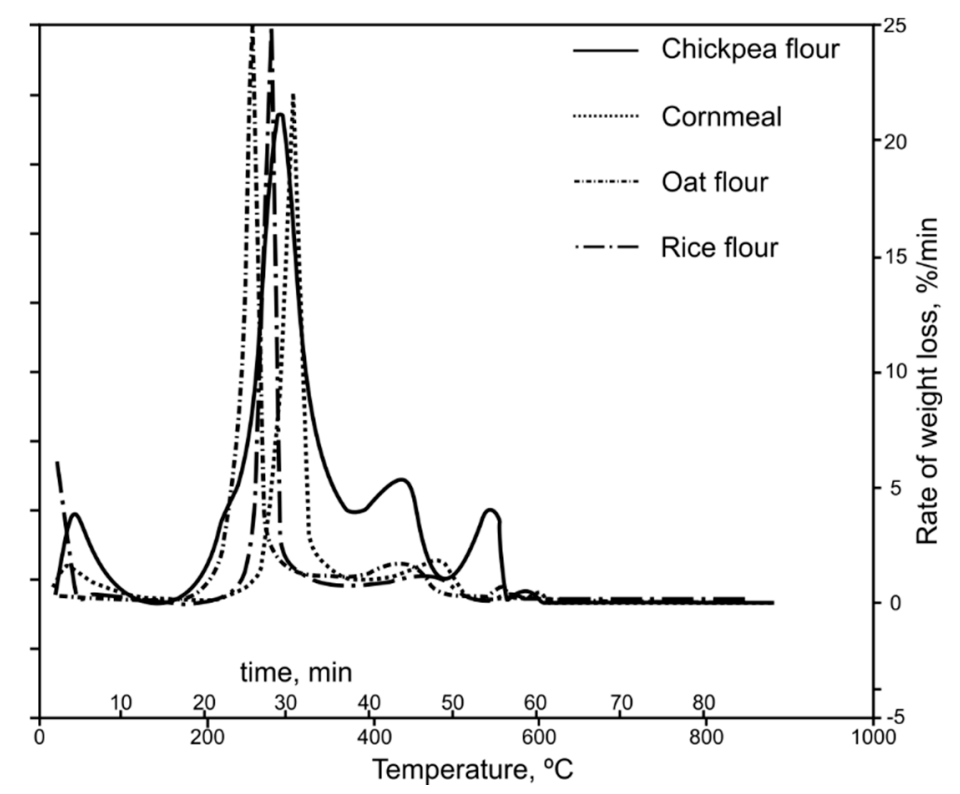

Figure 2. Presentation of the courses of derivative value of sample mass loss over time.

\subsection{Heat of Combustion}

Values of combustion heat are presented in Table 4.

Table 4. Delimited values of heat of combustion for the tested samples.

\begin{tabular}{ccccc}
\hline & Chickpea Flour Dust & Rice Flour Dust & Cornmeal Dust & Oat Flour Dust \\
\hline $\begin{array}{c}\text { Heat of combustion } \\
(\mathrm{kJ} / \mathrm{g})\end{array}$ & 16.525 & 14.325 & 15.223 & 17.252 \\
\hline
\end{tabular}

The determined values of combustion heat for the studied samples proved to be similar and are contained within a range typical for this type of samples (14 to $18 \mathrm{~kJ} / \mathrm{g}$ ). In general, heat of combustion might affect the course of explosion. The higher the value of the parameter, the more heat will be released during combustion. It will lead to higher pressures, resulting from higher gas temperatures. Therefore, $\mathrm{p}_{\max }$ and $(\mathrm{dp} / \mathrm{dt})_{\max }$ are expected to increase together with the heat of combustion. Although the course of explosion is determined by many parameters, and the impact of heat of combustion of the samples should not be considered solely, the following results of the explosion venting area calculations show some dependencies. For the test samples, the higher the value of the heat of combustion, the higher the required explosion venting area. However, because of the low number of samples tested, this conclusion should be validated in further research, together with other explosion indices.

\subsection{Vent Area Calulation}

The conducted calculations depict the actual impact of the type of flour on safety conditions connected with their processing, transport or storage. The decisive factor is the required maximum reduced explosion pressure $\left(\mathrm{p}_{\mathrm{red}, \max }\right)$. The results of the calculations are presented in Figure 3. The calculated explosion of venting area $A$ over the length/diameter ratio $(L / D)$ is presented for the different required reduced explosion pressures. 


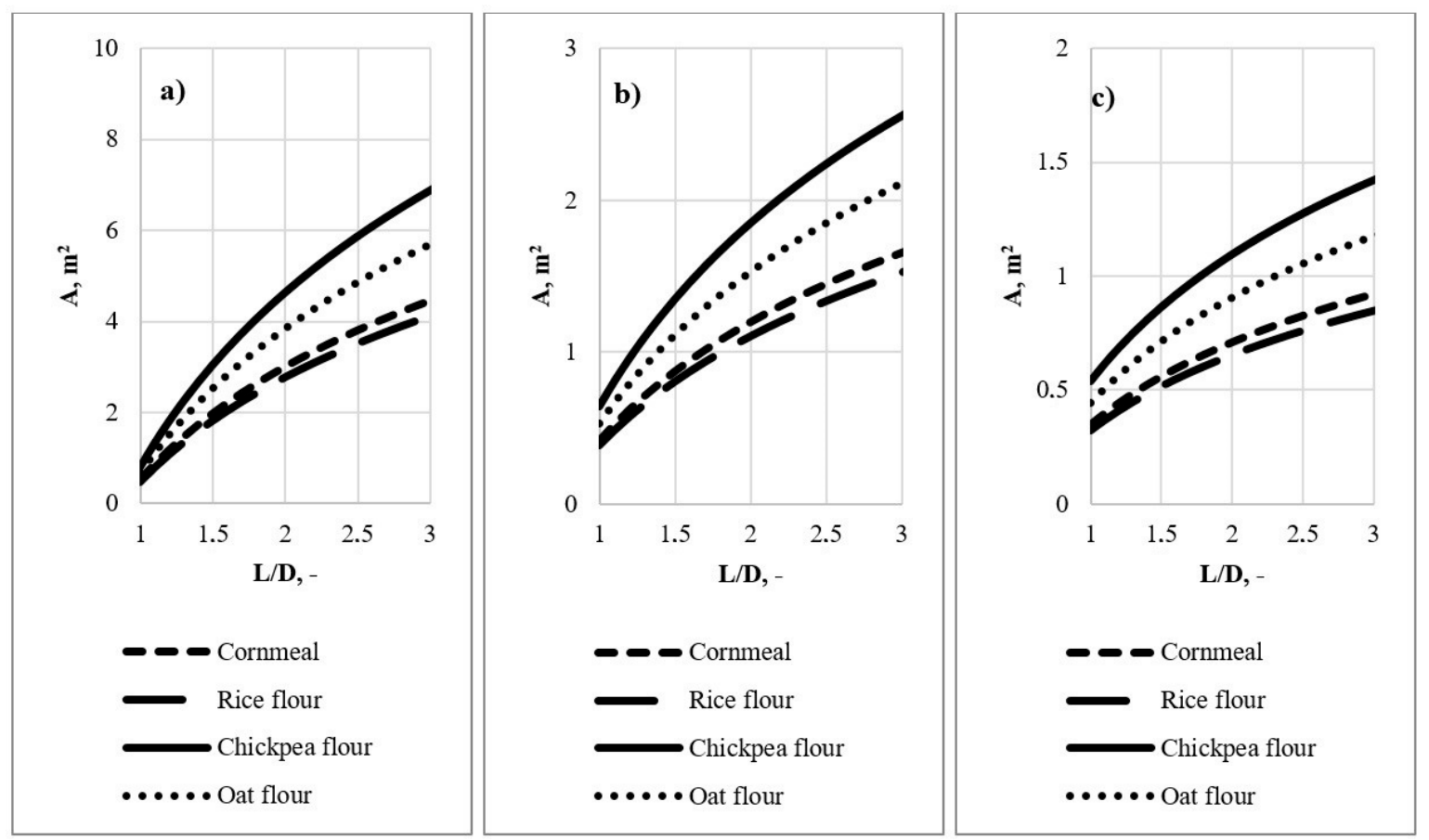

Figure 3. Calculated minimum vent areas for the analyzed flour dusts depending on the required reduced explosion pressure: (a) $p_{\max , \text { red }}=0.12$ bar; (b) $p_{\max \text {, red }}=0.24$ bar; $p_{\max \text {, red }}=0.4$ bar.

The results of the conducted calculations enable the devising of an analysis of empirical dependencies specified in the standard. A decisive parameter, on which depends the required explosion venting areas, is the required maximum reduced explosion pressure. The lower the designed value $p_{\text {red, }}$ max, the quicker the increase in the value of surface $A$ for the growing relation of the container length to its diameter $(L / D)$.

Furthermore, the presented dependencies also indicate that chickpea flour poses the greatest hazard from among the studied samples, while cornmeal is an example of a substance that poses a clearly smaller hazard. The remaining samples give rise to intermediate values. It should be borne in mind that, in the case of elongated containers $(L / D=3)$, the difference in the required size of the relieving surface for those samples amounted to as much as $\sim 75 \%\left(4 \mathrm{~m}^{2}\right.$ as compared to almost $7 \mathrm{~m}^{2}$, Figure 3a). Therefore, silo manufacturers must predict crucial operating conditions (including the explosive indices of the material stored) during the design stage to ensure safe exploitation during the whole life cycle.

Applying the above results of calculations allows controlling for the possible release of hazardous substance to the environment. On the other hand, the adoption of an insufficient relieving surface would cause an exceeding of the maximum pressure admissible for the given structure and its partial or complete destruction. In such a case, it is not easy to anticipate the consequences of this type of event or its impact on its surroundings.

\section{Discussion}

Results of the conducted standard-specific calculations point to the necessity of adopting a cautious approach to changes of the stored medium. As has been shown, disparities among results obtained for the tested flour types were considerable; they are, in particular, significant for lower designed values of $p_{\text {red,max }}$ which indicates that, in the event of an explosion, the change of stored material might not necessarily assure the desired safety level.

It ought to be emphasized that the executed calculations pertain to the required relieving surface in the defined initial conditions. In practical terms, it is also necessary to take into account the effectiveness 
of relieving the device being used, if it is smaller than one. This in turn implies that the effective relieving surface for such a device is lower in such a case than its nominal surface.

In the presented study, diameter $D$ of the silo was set as a parameter for the explosion venting area calculations, whereas silo length $L$ was fixed to $6.5 \mathrm{~m}$. The calculations were conducted for $L / D$ ratios between 1 and 3 . It should be underlined, that the dimensions of silos in real applications differ widely, depending on local conditions, compatibility with existing installations, or other requirements predefined by the user. However, the chosen silo dimensions were supposed to constitute a representative example. The structures used to store flour are usually elongated with the $L / D$ ratio higher than 1 . The approach enabled us to show the impact of an increase in the $L / D$ ratio on calculation results and was used by other authors as well [21].

The determined values of the bulk density of the test samples differed. This might be linked with the non-uniformed shape of the dusts studied. Similar conclusions were described in the literature [28].

It should be mentioned that the measurement uncertainties, typical for $\mathrm{K}_{\mathrm{St}}$ determination, significantly influence the results of explosion venting area calculation.

\section{Conclusions}

The obtained results of explosiveness parameters allow for making the presumption that all the studied foodstuff dusts were characterized by an explosion hazard which was not negligible. The highest values of such parameters, such as $p_{\max }$ and $(\mathrm{dp} / \mathrm{dt})_{\max }$, were recorded for the tested chickpea flour dust. Also, for this particular dust, the lowest explosion level was recorded. The lowest values of parameters $p_{\max }$ and $(\mathrm{dp} / \mathrm{dt})_{\max }$ were recorded for cornmeal dust; on the other hand, the LEL for this dust was found to be the highest. The tested cornmeal dust and oat flour dust achieved similar results for tested explosiveness parameters.

All studied dusts were classified to class 1 explosion hazard pursuant to the $\mathrm{K}_{\mathrm{St}}$ constant. This means that those dusts were characterized by weak explosive properties. Based on the abovementioned results, there is a need of applying appropriate explosion protection means in those plants where production, processing, storage, and hauling of the tested dusts takes place. In addition, it is also necessary to avoid the formation of a dust and air mixture which may explode.

The results of the heat of combustion determination did not appear to be in direct relation with the obtained explosiveness parameters. Consequently, on their basis, it is impossible to relate in an unequivocal way to the real hazard level and the possibility of releasing hazardous substances into the environment.

The results obtained during the analyses of the thermal decomposition of the studied samples point to certain differences ascertained for the chickpea flour dust as compared to the remaining samples for which the obtained results were similar. Earlier commencement of thermal decomposition, as well as the lower temperature of the maximum sample mass loss, seemed to be the reason why this material obtained the highest explosion pressure parameters as well as its derivative after time.

Despite the fact that the values of the calculated indexes $\mathrm{K}_{\mathrm{St}}$ of the studied dusts were contained within the range of 50 to $85 \mathrm{bar} \cdot \mathrm{m} / \mathrm{s}$, clear differences may be ascertained in the required total surface of devices used to vent the explosion. As the desired reduced explosion pressure decreased, the abovementioned difference increased. For pred,max equal to 0.12 bar, for a sample of chickpea flour, the required relieving surface was $75 \%$ higher compared to a sample of cornmeal which may affect the necessity of modifying the silo's structure or the device used to convey flour.

Anthropogenic emissions arising from industrial activity and traffic are considered to be the main source of air pollution; nevertheless, emission of dusts and their products of thermal and combustion products into the atmosphere should not be overlooked during emergency events and during normal operation. Dust explosions in the processing industries practically always start inside process equipment such as mills, dryers, mixers, classifiers, conveyors, and storage silos and hoppers. If the rate at which the growth of pressure takes place and the value of dust concentration indispensable to creating a hazard, including the maximum explosion pressure, is enough, such processes may be 
prevented among others, for example, by using relieving surfaces for those dynamic phenomena. One of the features of air pollution is the possibility of moving; hence, if the maximum increase rate of dust explosion pressure is known, it becomes possible to select ways of protecting from uncontrolled energy release, emission of dusts, and products of their thermal decomposition and combustion.

Flour storage and transportation systems are threatened by dust explosions. According to the "principles of integrated explosion safety" [12], the limitation of flame and explosion pressure range is the latest safety measure. Storage and transportation system must be designed in a way that it will withstand the overpressures created during an explosion. Therefore, the role of explosion venting is to decrease the pressure level to the desired level. On the other hand, the consequences of an inappropriate approach might be serious for the local environment. The destruction of the installation, resulting from increased static pressure $p_{\text {stat}}$, will often lead to the subsequent spread of fire or, in worst case, to the domino effect. Similar disasters, resulting in many causalities, immense material losses, and enormous emission of thermal decomposition products to the atmosphere, have already been recorded, e.g., The Continental Grain elevator in Westwego (Louisiana, United States) explosion in December of 1977 [29].

Future research should focus on other safety issues connected with flour storage and transportation systems. Structure rupture and the resulting release of the combustion products to the ambient atmosphere might occur not only due to the insufficient explosion of venting areas. The explosion, if not properly vented and/or isolated, may cause detonation, especially in elongated spaces such as pipelines. Therefore, deflagration to detonation transition of the flour dusts should be studied.

The other aspect of great importance is the volatility of the dusts in the food industry. It should be kept in mind that the first principle of integrated safety requires the avoidance of the creation of an explosive atmosphere. Moreover, this knowledge should be presented to a wider audience in order to raise the awareness of relevant communities.

Author Contributions: Conceptualization, M.P. and S.P.; methodology, M.P. and S.P.; formal analysis, M.P. and S.P.; investigation, M.P. and S.P.; resources, M.P. and S.P.; writing-original draft preparation, M.P. and S.P.; writing—review and editing, M.P. and S.P.; visualization, M.P. and S.P.; supervision, M.P. and S.P.

Funding: This research received no external funding.

Conflicts of Interest: The authors declare no conflict of interest.

\section{References}

1. Eckhoff, R.K. Dust Explosions in the Process Industries, 3rd ed.; Gulf Professional Publishing: New York, NY, USA, 2003; pp. 29-32.

2. Abbasi, T.; Abbasi, S.A. Dust Explosions-Cases, Causes, Consequences, and Control. J. Hazard. Mater. 2007, 140, 7-44. [CrossRef] [PubMed]

3. Krzyżanowski, M. WHO Air Quality Guidelines for Europe. J. Toxicol. Environ. 2008, 71, 47-50. [CrossRef] [PubMed]

4. Malec, A.; Borowski, G. Zagrożenia Pyłowe Oraz Monitoring Powietrza Atmosferycznego. Inz. Ekol. 2016, 50, 161-170. [CrossRef]

5. Imperial Sugar Company Dust Explosion and Fire. Available online: www.csb.gov/imperial-sugar-companydust-explosion-and-fire/ (accessed on 15 November 2019).

6. Pak, S.; Jung, S.A.; Roh, C.; Kang, C. Case Studies for Dangerous Dust Explosions in South Korea during Recent Years. Sustainability 2019, 11, 4888. [CrossRef]

7. Yuan, Z.; Khakzad, N.; Khan, F.; Amyotte, P. Dust Explosions: A Threat to the Process Industries. Process Saf. Environ. Environ. Prot. 2015, 98, 57-71. [CrossRef]

8. Washburn A Mill Explosion, 1878. Available online: www.mnopedia.org/event/washburn-mill-explosion1878 (accessed on 15 November 2019).

9. Dust Potential Factor in Statesville Flour Mill Explosion. Available online: www.wsoctv.com/news/local/ dust-potential-factor-statesville-flour-mill-explo/334630560 (accessed on 15 November 2019). 
10. Ramirez, A.; Garcia-Torrent, J.; Aguado, P.J. Determination Of Parameters Used To Prevent Ignition Of Stored Materials And To Protect Against Explosions In Food Industries. J. Hazard Mater. 2009, 168, 115-120. [CrossRef] [PubMed]

11. Smyth, S.; Cox, B.; Hetrick, T.; Ogle, R. Lessons Learned From A Milling Explosion. J. Loss Prev. Process Ind. 2019, 62, 103928. [CrossRef]

12. Eckhoff, R.K. Differences and Similarities of Gas and Dust Explosions: A Critical Evaluation of The European 'ATEX' Directives in Relation to Dusts. J. Loss Prev. Process Ind. 2006, 19, 553-560. [CrossRef]

13. Eckhoff, R.K. Understanding Dust Explosions. The Role of Power Science and Technology. J. Loss Prev. Process Ind. 2009, 22, 105-116. [CrossRef]

14. Taveau, J. Dust Explosion Propagation and Isolation. J. Loss Prev. Process Ind. 2017, 48, 320-330. [CrossRef]

15. Skjeltorp, A.T.; Hagdahl, T.; Jenssen, A. Underground Ammunition Storage. Blast Propagation in the Tunnel System. Report II A. Chamber Pressure, 1st ed.; Norwegian Defence Construction Service: Raufoss, Norway, 1975; pp. 6-11.

16. Taveau, J. Correlations for Blast Effects From Vented Dust Explosions. J. Loss Prev. Process Ind. 2010, 23, 15-29. [CrossRef]

17. Pressure Venting of Dust Explosions; VDI 3673, Part 1; Verein Deutscher Ingenieure: Düsseldorf, Germany, 2002.

18. Dust Explosion Venting Protective Systems; EN 14491; Comite Europeen de Normalisation: Brussels, Belgium, 2012.

19. Standard on Explosion Protection by Deflagration Venting; NFPA 68; National Fire Protection Association: Quincy, MA, USA, 2018.

20. Tascon, A. Design of silos for Dust Explosions: Determination of Vent Area Sizes and Explosion Pressures. Eng. Struct. 2017, 134, 1-10. [CrossRef]

21. Tascon, A.; Ramirez-Gomez, A.; Aguado, P.J. Dust Explosions in an Experimental Test Silo: Influence of Length/Diameter Ratio on Vent Area Sizes. Biosyst. Eng. 2016, 148, 18-33. [CrossRef]

22. Proust, C. Dust Explosions in Pipes: A Review. J. Loss Prev. Process Ind. 1996, 9, 267-277. [CrossRef]

23. Determination of Explosion Characteristics of Dust Clouds. In Determination of the Maximum Explosion Pressure Pmax of Dust Clouds; EN 14034, Part 1; Comite Europeen de Normalisation: Brussels, Belgium, 2011.

24. Determination of Explosion Characteristics of Dust Clouds. In Determination of the Maximum Rate of Explosion Pressure Rise (dp/dt) max of Dust Clouds; EN 14034, Part 2; Comite Europeen de Normalisation: Brussels, Belgium, 2011.

25. Determination of Explosion Characteristics of Dust Clouds-Part 3: Determination of the Lower Explosion Limit LEL of Dust Clouds; EN 14034, Part 3; Comite Europeen de Normalisation: Brussels, Belgium, 2006.

26. Plastics-Thermogravimetry (TG) of Polymers_Part 1: General Principles; EN ISO 11358, Part 1; Comite Europeen de Normalisation: Brussels, Belgium, 2014.

27. Reaction to Fire Tests for Products. In Determination of The Gross Heat of Combustion (Calorific Value); EN ISO 1716; Comite Europeen de Normalisation: Brussels, Belgium, 2018.

28. Schuchmann, H.; Gerhards, C. Influence of particle size distribution on bulk density and flow-ability of vending powders. In Proceedings of the 7th International Congress on Engineering and Food, Brighton, UK, 13-17 April 1997; Continuum International Publishing Group Ltd.: Sheffield, UK, 1997.

29. Cheremisinoff, N.P. Dust Explosion and Fire Prevention Handbook: A Guide to Good Industry Practices, 1st ed.; Scrivener Publishing Publishing: Beverly, CA, USA, 2014; pp. 53-54.

(C) 2019 by the authors. Licensee MDPI, Basel, Switzerland. This article is an open access article distributed under the terms and conditions of the Creative Commons Attribution (CC BY) license (http://creativecommons.org/licenses/by/4.0/). 